\title{
Collagen biology for bone regenerative surgery
}

\author{
Masaru Murata \\ Department of Oral and Maxillofacial Surgery, Health Sciences University of Hokkaido, Hokkaido, Japan
}

\begin{abstract}
J Korean Assoc Oral Maxillofac Surg 2012;38:321-5)
Collagen is widely used for regenerative therapy and pharmaceutical applications as one of the most useful scaffolds. Collagen is the most abundant protein in vertebrates and the natural substrate of various types of animal cells. Bone and dentin are mineralized tissues and almost similar in chemical components. They consist of collagen (18\%), non-collagenous proteins ( $2 \%)$, hydroxyapatite $(70 \%)$ and body fluid (10\%) in weight volume. Pepsindigested, type I collagen (atelocollagen) and heat-denatured collagen (gelatin) are basic collagenous materials for medical use. Demineralized dentin matrix (DDM) and demineralized bone matrix (DBM) belong to acid-insoluble group, and vital tooth-derived DDM is a unique dentin material including cementum and growth factors. In this review, collagen-based materials will be introduced and discussed for bone regenerative surgery.
\end{abstract}

Key words: Collagen, Biomaterial, Dentin, Bone, Regeneration

[paper submitted 2012.11. 1 / accepted 2012. 11. 8]

\section{Introduction}

Regenerative medicine is based on biomaterials science and cell biology. Our generation must have enough knowledge for collagen and hydroxyapatite that are main components in bone and tooth. Doctors with the knowledge of biomaterials science and pathology never use a bone wax with paraffin and other agents (so-called beeswax). Though the bone wax was developed for stopping the marrow bleeding, it should inhibit bone regeneration as a foreign body and form foreign granuloma. Nowadays, cleaver dental surgeons ought to use collagenous materials for blood clot and bone regeneration.

\section{Bone and Dentin}

Osteoblasts and odontoblasts produce calcifiable collagen matrix $^{1}$. Bone and dentin are mineralized tissues and almost similar in chemical components ${ }^{2}$. They consist of collagen

\section{Masaru Murata}

Department of Oral and Maxillofacial Surgery, Health Sciences University of Hokkaido, 1757 Kanazawa, Tobetsu, Hokkaido 061-0293, Japan

TEL: +81-133232921 FAX: +81-133231429

E-mail:murata@hoku-iryo-u.ac.jp

(c) This is an open-access article distributed under the terms of the Creative Commons Attribution Non-Commercial License (http://creativecommons.org/licenses/by-nc/3.0/), which permits unrestricted non-commercial use, distribution, and reproduction in any medium, provided the original work is properly cited.
(18\%), non-collagenous proteins $(2 \%)$, hydroxyapatite $(70 \%)$ and body fluid (10\%) in weight volume.(Fig. 1) The matrix is a repository of growth factors such as bone morphogenetic proteins (BMPs), transforming growth factor- $\beta$ (TGF- $\beta$ ), insulin-like growth factor (IGF), and basic fibroblast growth factor (bFGF) ${ }^{3-5}$. Several non-collagenous proteins such as osteocalcin (OCN) and osteopontin (OPN) are common in bone and dentin, while dentin phosphoprotein (DPP) (socalled phosphophoryn) is a specific non-collagenous protein in dentin ${ }^{6}$. Phosphophoryn consists of Asp (35\%) and

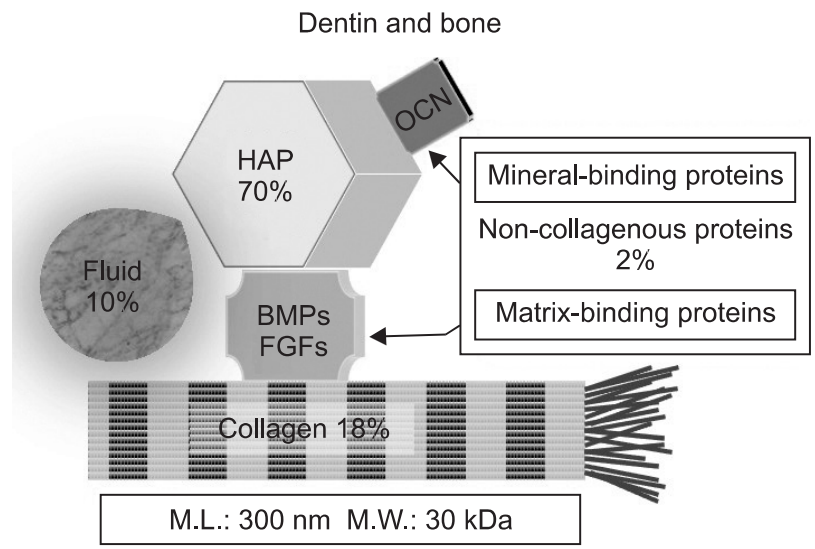

Fig. 1. Diagram of common components in dentin and bone. (HAP: hydroxyapatite, OCN: osteocalcin, BMP: bone morphogenetic protein, FGFs: fibroblast growth factors)

Masaru Murata: Collagen biology for bone regenerative surgery. J Korean Assoc Oral Maxillofac Surg 2012 
Ser $(40 \%)$ and another amino acids $(25 \%)$ in the amino acid components. In addition, bone is cellular matrix with capillary, but dentin is acellular, dense matrix with dentinal tubes. The structural differences between them are the most important points for the release of growth factors and the absorbability of extracellular matrix (ECM).

\section{Collagen}

Collagen is the most abundant protein in vertebrates and the natural substrate of various types of animal cells. Type I collagen is main component in bone and dentin. The structure of type I collagen is well known as triple-helix. At molecular level, one finds tropocollagen, which is a subunit of the sum of collagen that forms fibrils that are 300 $\mathrm{nm}$ long and $1.5 \mathrm{~nm}$ in diameter, consisting 3 polypeptide strands known as $\alpha$ chains. Each of these strands possesses the conformation of a left-handed helix. As the non-helical telopeptide region of the collagen molecule can produce an antigenic response by the host, the immunogenicity of the collagen is reduced by a pepsin digestion ${ }^{7}$. The telopeptidedepleted type I collagen (so-called atelocollagen), therefore, has been prepared from skin, bone, tendon or pericardium for medical uses. Characteristic features of collagen are its ability to form supra-molecular aggregates in extracellular space and to become cellular ancharage ${ }^{8}$.

\section{Collagenous Biomaterials}

Now, collagen is widely used for regenerative therapy and pharmaceutical applications as one of the most useful scaffolds. The first collagen-based biomaterial was developed in $1980^{9,10}$, and has been modified in terms of antigenicity and structure for cellular response. We can classify collagen into the acid-soluble group and the acidinsoluble group.(Fig. 2) Generally, commercially available collagenous materials are produced from acid-soluble, pepsin-digested collagen (atelocollagen) and heat-denatured collagen (so-called gelatin).(Figs. 3. A, 3. B) Several collagenous materials are available in various forms such as solution, sponge, membrane, bead, mini-pellet and gel. Recently, a dry composite sponge of fibrillar atelocollagen and gelatin has been developed to reduce the inflammatory response and increase cellular affinity and ingrowth ${ }^{7}$. The insolubility of collagen is relatively high for a fibrillar structure and superior in physical strength to gelatin ${ }^{7,11}$. The collagenous materials did not show interference with bone

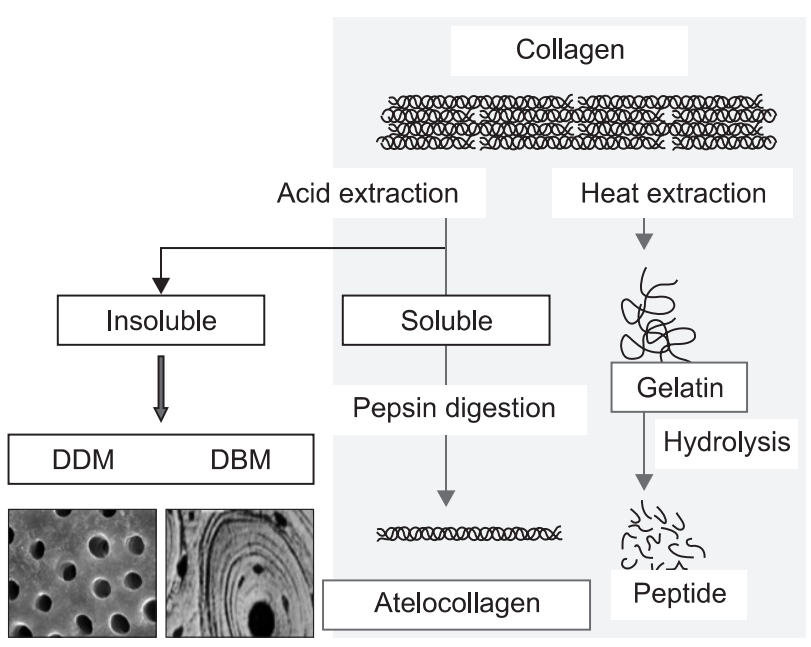

Fig. 2. Preparation method for collagenous materials. Atelocollagen: acid-soluble matrix, DDM and DBM: acid-insoluble matrix. (DDM: demineralized dentin matrix, DBM: demineralized bone matrix)

Masaru Murata: Collagen biology for bone regenerative surgery. J Korean Assoc Oral Maxillofac Surg 2012

formation at the implanted site ${ }^{12-14}$. The fibrillar atelocollagen reconstituted from bovine skin collagen was found to produce significantly more new bone than non-graft in bone defects ${ }^{14}$. Atelocollagen/heat-denatured collagen ${ }^{14}$, phosphophoryn/ $\mathrm{Ca}^{2+} /$ collagen $^{15}$ and hyaluronate/cross-linking collagen ${ }^{16}$ were estimated in the mandibular defects of rabbits, in the femur defect of beagle dogs, in the cranial defect of rats, respectively. These biomaterials demonstrated good biocompatibility and exhibited osteoconductive potential ${ }^{14-16}$, whereas synthetic polymers are not osteoconductive ${ }^{17,18}$.

The characteristic features of collagen are its cell-attachment capability (RGD sequence), excellent tissue compatibility, absorbability and weak antigenicity ${ }^{7,8}$. The absorption of collagenous materials depends on a combination of enzymes such as collagenase and gelatinase, and cellular phagocytosis $^{11,19}$. Moreover, the clinical advantages of collagen-based materials are an easy handling for contour formation, adaptation to various shapes and moisture power. All cells never invade into dry areas without body fluids.

\section{BMPs}

BMPs belong to non-collagenous proteins and are members of TGF- $\beta$ superfamily ${ }^{20,21}$. In 1997, the first clinical studies have been published by using recombinant human BMP-2 and atelocollagen sponge $\mathrm{e}^{22,23}$. Boyne and co-worker ${ }^{22}$ implanted the BMP-2/atelocollagen sponge for the sinus liftings of 12 edentulous or partially edentulous patients with severe atrophy 

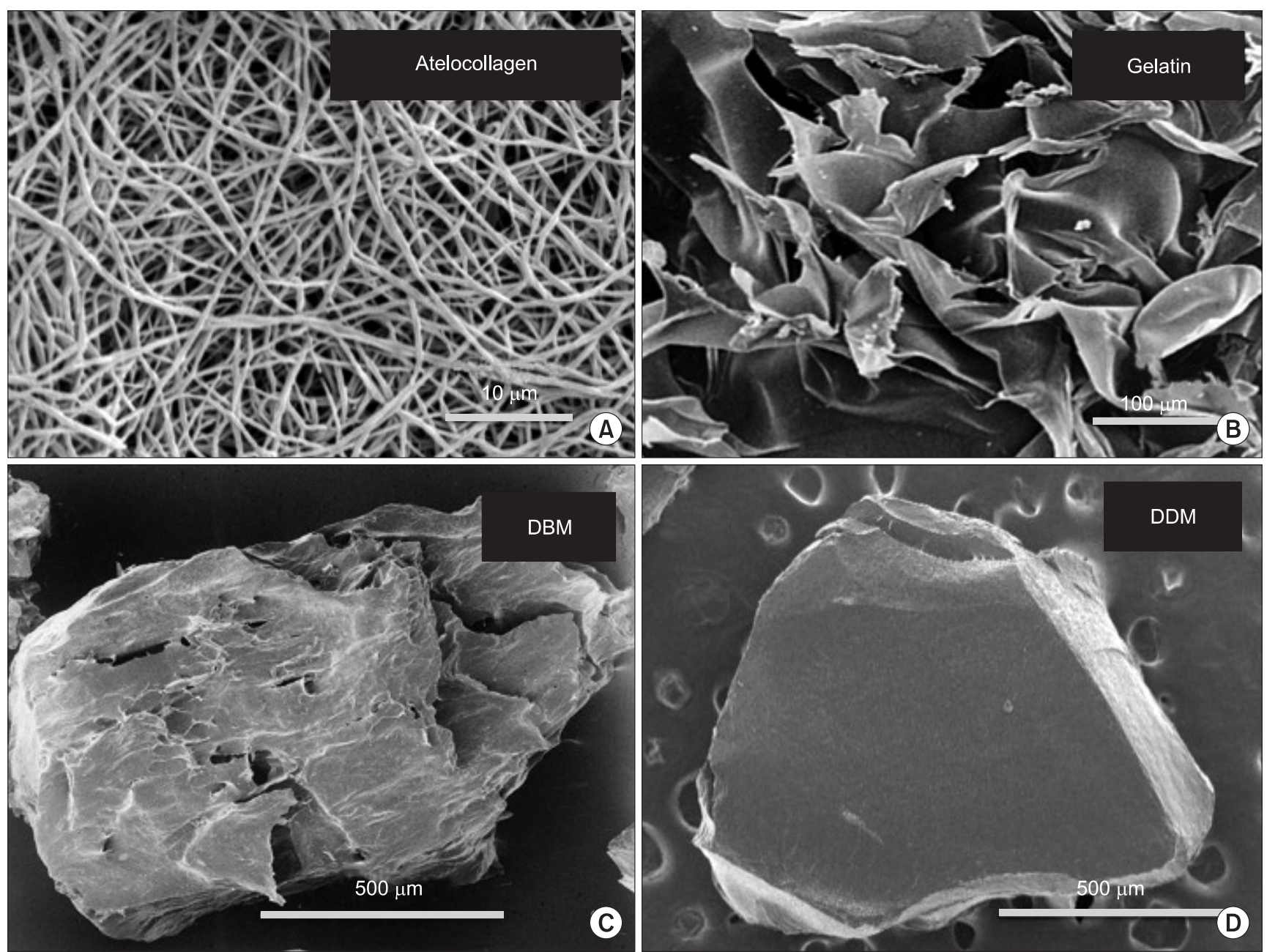

Fig. 3. SEM of collagenous materials. A. Atelocollagen fibers. B. Plate-like gelatin. C. DBM particle. D. DDM particle. (DBM: demineralized bone matrix, DDM: demineralized dentin matrix)

Masaru Murata: Collagen biology for bone regenerative surgery. J Korean Assoc Oral Maxillofac Surg 2012

of the maxilla. The results indicated that the subsequent increase in height of the treated maxilla varied between 2.3 and $15.7 \mathrm{~mm}$. The OP-1 (BMP-7) device, demineralized bone matrix and autogenous bone were grafted for human sinus floor elevation in $1999^{24}$. The addition of BMPs to atelocollagen fibers enhanced the absorption rate of the collagen scaffold ${ }^{25-27}$. On the other hand, non-absorbable materials remain in tissue as foreign bodies for a life time and should trigger chronic inflammation. The use of bioabsorbable materials is, therefore, scientifically preferable and there is a medical need for graft materials that both allow for bone formation and gradually absorb as to be replaced by bone. We found that the atelocollagen sponge facilitated its adaptation of the skull arch and was slowly absorbed as new bone began to form in the presence of BMP- $2^{28,29}$.

\section{Autograft of Bone and Dentin}

In 1820, human bone autograft was carried out by Walther. In 2002, human dentin autograft was achieved for sinus lifting by Murata ${ }^{30}$ who published the first clinical case in International Association for Dental Research, 2003. Dentin autograft is an advanced therapy proposed by Asian dental surgeons. The clinical time lag is 182 years between the bone graft and the dentin graft.

Urist $^{20}$ discovered in 1965 that rabbit demineralized bone matrix (DBM) induced bone in muscle tissues until 8 weeks after implantation. Urist's group also confirmed in 1967 that rabbit demineralized dentin matrix (DDM) and calcified dentin induced bone in muscle tissues at 4 weeks, at 8-12 weeks, respectively ${ }^{31,32}$. These results indicate DDM has better performance in bone induction than calcified dentin. 
We confirmed that human DBM and DDM induced bone and cartilage in the subcutaneous tissues of nude-mice at 4 weeks $^{33}$. DBM and DDM are defined as acid-insoluble, collagenous matrics with growth factors ${ }^{34-37}$.(Figs. 3. C, 3. D) Autogenous DDM can be recycled without antigenesity for bone regeneration.

In 2007, the immediate autograft of DDM could be achieved using newly developed mill (Osteo-Mill; Tokyo Iken Co., Ltd., Tokyo, Japan) for tooth crush. The particles after $2 \%$ $\mathrm{HNO}_{3}$-demineralization was proven to be bacteria-free by bacteriological examination. The histological findings of biopsy revealed mature bone in the spaces created by absorption of DDM, and connected directly with DDM residues. Successful cases of DDM autograft have been acquired by the innovative processing system. Medical service company (Korea Tooth Bank Co., Ltd., Seoul, Korea) was established in 2009, and various tooth-derived materials of sizes, hardness, and shapes have been delivered into hospitals and clinics for bone regeneration ${ }^{38-41}$. Dentin collagen is hardest among the body collagens. The hardness with cross-linking and the elasticity after the acid treatment are crucial advantages especially for vertical bone augmentation, based on doctor's idea.

\section{Conclusion}

Doctors must select and combine better performance substances among many graft materials for patients. Standardized operations for regeneration will be basically biomaterialbased therapy. Regenerative medicine is based on advanced biomaterials science and cell biology. An interdisciplinary approach of researches in the medical and engineering fields is very crucial for wonderful success. This review introduced collagen biology and Asian innovative technology for our own day and near bright future.

\section{References}

1. Jee WSS. The skeletal tissue. In: Weiss L, ed. Histology: cell and tissue biology. London: The MacMillan Press; 1983:225-8.

2. Ham AW, Cormack DH. Ham's histology. 9th ed. Philadelphia: Lippincott; 1987:264-320.

3. Reddi AH. Regulation of bone differentiation by local and systemic factors. In: Peck WA, ed. Bone and mineral research. Amsterdam: Elsevier; 1985:27-47.

4. Solheim E. Growth factors in bone. Int Orthop 1998;22:410-6.

5. Wozney JM. Bone morphogenetic proteins. Prog Growth Factor Res 1989;1:267-80.

6. Prasad M, Butler WT, Qin C. Dentin sialophosphoprotein in biomineralization. Connect Tissue Res 2010;51:404-17.

7. Koide M, Osaki K, Konishi J, Oyamada K, Katakura T, Takahashi A, et al. A new type of biomaterial for artificial skin: dehydrothermally cross-linked composites of fibrillar and denatured collagens. J Biomed Mater Res 1993;27:79-87.

8. Kleinman HK, Klebe RJ, Martin GR. Role of collagenous matrices in the adhesion and growth of cells. J Cell Biol 1981;88:473-85.

9. Yannas IV, Burke JF. Design of an artificial skin. I. Basic design principles. J Biomed Mater Res 1980;14:65-81.

10. Yannas IV, Burke JF, Gordon PL, Huang C, Rubenstein RH. Design of an artificial skin. II. Control of chemical composition. J Biomed Mater Res 1980;14:107-32.

11. Huang CYI. Mechanochemical studies of enzymatic degradation of insoluble collagen fibers. Biomed Mater 1977;11:137-54.

12. Rocha LB, Goissis G, Rossi MA. Biocompatibility of anionic collagen matrix as scaffold for bone healing. Biomaterials 2002;23: 449-56.

13. Rosa FP, Lia RC, de Souza KO, Goissis G, Marcantonio EJ. Tissue response to polyanionic collagen: elastin matrices implanted in rat calvaria. Biomaterials 2003;24:207-12.

14. Maki F, Murata M, Kitajo H, Sato D, Taira H, Arisue M. Bone healing in large mandibular defects without periosteum in adult rabbits: a new application of collagenous sponge for bone regeneration. J Hard Tissue Biol 2000;9:56-62.

15. Sauk JJ, Van Kampen CL. Use of a phosphophoryn-Ca(+2)collagen composition that mimics a mineralization front in unicortical defects in long bones. J Biomed Mater Res 1991;25:60919.

16. Liu LS, Thompson AY, Heidaran MA, Poser JW, Spiro RC. An osteoconductive collagen/hyaluronate matrix for bone regeneration. Biomaterials 1999;20:1097-108.

17. Meikle MC, Papaioannou S, Ratledge TJ, Speight PM, Watt-Smith SR, Hill PA, et al. Effect of poly DL-lactide--co-glycolide implants and xenogeneic bone matrix-derived growth factors on calvarial bone repair in the rabbit. Biomaterials 1994;15:513-21.

18. Verheyen CC, de Wijn JR, van Blitterswijk CA, de Groot K, Rozing PM. Hydroxylapatite/poly(L-lactide) composites: an animal study on push-out strengths and interface histology. J Biomed Mater Res 1993;27:433-44.

19. Salthouse TN. Cellular enzyme activity at the polymer-tissue interface: a review. J Biomed Mater Res 1976;10:197-229.

20. Urist MR. Bone: formation by autoinduction. Science 1965;150: 893-9.

21. Wozney JM, Rosen V, Celeste AJ, Mitsock LM, Whitters MJ, Kriz $\mathrm{RW}$, et al. Novel regulators of bone formation: molecular clones and activities. Science 1988;242:1528-34.

22. Boyne PJ, Marx RE, Nevins M, Triplett G, Lazaro E, Lilly LC, et al. A feasibility study evaluating rhBMP-2/absorbable collagen sponge for maxillary sinus floor augmentation. Int J Periodontics Restorative Dent 1997;17:11-25.

23. Howell TH, Fiorellini J, Jones A, Alder M, Nummikoski P, Lazaro $\mathrm{M}$, et al. A feasibility study evaluating rhBMP-2/absorbable collagen sponge device for local alveolar ridge preservation or augmentation. Int J Periodontics Restorative Dent 1997;17:124-39.

24. Groeneveld EH, van den Bergh JP, Holzmann P, ten Bruggenkate CM, Tuinzing DB, Burger EH. Histomorphometrical analysis of bone formed in human maxillary sinus floor elevations grafted with OP-1 device, demineralized bone matrix or autogenous bone. Comparison with non-grafted sites in a series of case reports. Clin Oral Implants Res 1999;10:499-509.

25. Hollinger JO, Schmitt JM, Buck DC, Shannon R, Joh SP, Zegzula $\mathrm{HD}$, et al. Recombinant human bone morphogenetic protein-2 and collagen for bone regeneration. J Biomed Mater Res 1998;43:35664.

26. Omura S, Mizuki N, Kawabe R, Ota S, Kobayashi S, Fujita K. A carrier for clinical use of recombinant human BMP-2: dehydrothermally cross-linked composite of fibrillar and denatured atelocollagen sponge. Int J Oral Maxillofac Surg 1998;27:129-34.

27. Murata M, Huang BZ, Shibata T, Imai S, Nagai N, Arisue M. Bone 
augmentation by recombinant human BMP-2 and collagen on adult rat parietal bone. Int J Oral Maxillofac Surg 1999;28:232-7.

28. Murata M, Arisue M, Sato D, Sasaki T, Shibata T, Kuboki Y. Bone induction in subcutaneous tissue in rats by a newly developed DNA-coated atelocollagen and bone morphogenetic protein. Br J Oral Maxillofac Surg 2002;40:131-5.

29. Murata M, Maki F, Sato D, Shibata T, Arisue M. Bone augmentation by onlay implant using recombinant human BMP-2 and collagen on adult rat skull without periosteum. Clin Oral Implants Res 2000;11:289-95.

30. Murata M. Autogenous demineralized dentin matrix for maxillary sinus augmentation in humans: the first clinical report. Gothenburg: 81th International Association for Dental Research; 2003.

31. Yeomans JD, Urist MR. Bone induction by decalcified dentine implanted into oral, osseous and muscle tissues. Arch Oral Biol 1967;12:999-1008.

32. Bang G, Urist MR. Bone induction in excavation chambers in matrix of decalcified dentin. Arch Surg 1967;94:781-9.

33. Murata M, Akazawa T, Takahata M, Ito M, Tazaki J, Hino J, et al. Bone induction of human tooth and bone crushed by newly developed automatic mill. J Ceram Soc Japan 2010;118:434-7.

34. Sampath TK, Reddi AH. Homology of bone-inductive proteins from human, monkey, bovine, and rat extracellular matrix. Proc
Natl Acad Sci U S A 1983;80:6591-5.

35. Solheim E. Osteoinduction by demineralised bone. Int Orthop 1998;22:335-42.

36. Bessho K, Tanaka N, Matsumoto J, Tagawa T, Murata M. Human dentin-matrix-derived bone morphogenetic protein. J Dent Res 1991;70:171-5.

37. Murata M, Inoue M, Arisue M, Kuboki Y, Nagai N. Carrierdependency of cellular differentiation induced by bone morphogenetic protein in ectopic sites. Int J Oral Maxillofac Surg 1998;27: 391-6.

38. Kim YK, Kim SG, Byeon JH, Lee HJ, Um IU, Lim SC, et al. Development of a novel bone grafting material using autogenous teeth. Oral Surg Oral Med Oral Pathol Oral Radiol Endod 2010;109:496-503.

39. Park SM, Um IW, Kim YK, Kim KW. Clinical application of autotooth bone graft material. J Korean Assoc Oral Maxillofac Surg 2012;38:2-8.

40. Kim YK. Bone graft material using teeth. J Korean Assoc Oral Maxillofac Surg 2012;38:134-8.

41. Murata M, Akazawa T, Mitsugi M, Um IW, Kim KW, Kim YK. Human dentin as novel biomaterial for bone regeneration. In: Pignatero R, ed. Biomaterials. Croatia: Inteck Publisher; 2011: $127-40$. 